\title{
Education and Family Ties in Italy, France and Sweden
}

\author{
Giulia Assirelli \\ PhD student of Sociology and Social Research, University of Trento, Italy \\ giulia.assirelli@unitn.it \\ Marco Tosi \\ PhD student of Sociology and Social Research, University of Trento, Italy \\ marco.tosi@unitn.it
}

\section{Doi:10.5901/jesr.2013.v3n7p379}

\begin{abstract}
Education is actually a crucial element of social stratification. While research has often focused on education's effect on labor market opportunities and intergenerational class mobility, it has seldom been analyzed its association with the structure of family ties. However, as a consequence of unprecedented demographic changes, multigenerational bonds are becoming increasingly important for the solidarity within families and the future sustainability of welfare state. The main argument underlying this study is that individuals' level of education is likely to affect both the preferences and the structure of restrictions and opportunities. First, higher educated individuals are expected to acquire more individualistic values, and thus to be less oriented toward family issues. Second, the higher educated individuals are more likely to look for job opportunities in specific and selected areas, and thus to loosen family ties because of a greater geographical mobility.Moreover, the association between education and family ties is likely to be affected by the peculiar combination of institutional and cultural features. The country-specific context is, indeed, likely to pattern the structure of costs, opportunities, and individual preferences related to the maintenance of more-or-less strong intergenerational relations. Using data from Share 2004-2007, this paper assesses the effect of education on the relationships between family members in Italy, France and Sweden. In particular, empirical evidence is provided for parent-child geographical proximity and frequency of contacts.
\end{abstract}

\section{Introduction}

Sociological research has mostly focused on the effects of education on labor market opportunities and intergenerational class mobility. The existing literature shows that the higher the level of education, the higher is the probability of being employed, of finding better jobs, of earning higher wages, and of undertaking a process of upward mobility (Hout 2012). Far from eroding the family's cohesive role (Parson 1942), this process of class mobility does not seem to diminish the importance of intergenerational relations in the so-called 'modified extended family' (Litwak 1960). Indeed, a large strand of the literature has pointed out the enduring importance of intergenerational relations in contemporary societies and beyond the nuclear family (Kohli 1999; Bengtson 2001).

However, some scholars suggest the so-called hypothesis of 'family decline', according to which individualistic behaviors tend to prevail over the attitudes toward family (Inglehart 1977; Popenoe 1988). On the one hand, the increasing variation in family structure - i.e. the increasing rate of divorce, the growing female participation to the labor market, and the decrease in fertility rate - seems to reflect the changes in values and in intergenerational solidarity. On the other hand, at the micro level, this process of individualization is thought to be largely driven by the increase in educational attainment, which would trigger a substantial emancipation of the individual from his strongest ties (Beck 1986).

The empirical implications of this thesis have not been widely studied. The aim of this paper is to fill this gap, by analyzing the association between education and family ties. In particular, using data from 'Share' 2004 and 2007, this study analyses the influence of individual level of education on parent-child frequency of contacts and geographical proximity in three European countries, namely Italy, France, and Sweden.

These three countries differ in terms of both the institutional asset and the prevailing kinship tradition (Kalmijn and Saraceno 2008). Sweden is characterized by inclusive welfare state, flexible labor market and individualistic culture. At the opposite side, Italy has a sub-protective welfare state, a quite rigid labor market and a well-known familialistic tradition. France is representative of the continental welfare regime, but shares with Italy a quite strong familialism. Thus, 
we may expect to find different effects of education on family ties in the three countries, since the country-specific context is likely to pattern the structure of costs, opportunities, and individual preferences related to the maintenance of more-orless strong intergenerational relations.

The rest of the paper is structured as follows: the next paragraph outlines the theoretical framework and the main hypotheses concerning the effects of education on family ties, with particular emphasis on the frequency of parent-child contacts and on the geographical proximity between family members. Section 3 is devoted to the data and methods used for the analysis; in section 4 results are presented, and section 5 concludes.

\section{Theoretical framework and hypotheses}

The existing literature basically distinguishes between two possible mechanisms through which education may affect the strength of intergenerational ties (Klein Ikkink et al. 1999).

First, structural explanations focus on the structure of restrictions and opportunities for family interactions. One important factor which, according to this approach, is likely to influence the maintenance of close parent-child relations is represented by job opportunities. Some studies emphasize that the higher educated individuals are more likely to move in order to find better jobs; the labour market offering them more opportunities is, indeed, smaller and geographically circumscribed. On the contrary, unskilled workers are supposed to be able to find a well-matching job almost everywhere, that is to say without the necessity to move from their initial location (Litwak 1960a; Shelton and Grundy 2000). Thus, the cost-opportunity of geographical mobility is likely to significantly differ between the higher and the lower educated individuals.

Second, cultural explanations focus on the system of individual preferences, values, attitudes, and internalized norms, which is likely to be significantly shaped by education. According to this approach, the higher educated individuals have a different value orientation toward family, and they develop individualistic attitudes. In other words, the higher their levels of education, the more the individuals value their self-achievement, autonomy and independence. Thus, family ties are likely to be weakened by the tendency to substitute family-oriented attitudes with individual-oriented ones (Thornton and Young-DeMarco 2001).

A more recent strand of the literature suggests that education may have not only an absolute effect, but also a relative one, on family ties. This means that children's education plays a role not only per se, but also in relation with the parental one; in other words, differences in educational attainment within families are likely to influence the strength of parent-child relations. Again, this effect may be driven by both the value orientation and the structure of opportunities. On the one hand, parents and children with similar education more often share interests and values, and thus have closer relationships. On the other hand, family ties are likely to be strengthened by educational homogamy, because it favors the process of status achievement and reduces the cost-opportunity of maintaining closer relationships (Kalmijn 2006).

According to both the structural and the cultural approaches, we may expect that education has a positive effect on the distance from the parental home (H1). This may occur because higher educated individuals are more likely to look for a job in a geographically specific labor market, or because of their individualistic values and attitudes.

The diffusion of individualism is also likely to affect the intensity of child-parent relations, since - as we have previously argued - it implies a prevalence of individual-oriented behaviors over attitudes toward family. Thus, we may expect that the higher the level of education, the lower is the frequency of parent-child contacts ( $\mathrm{H} 2)$.

Moreover, education may have an indirect effect on the frequency of parent-child contacts, via distance: the more individuals are educated, the more distant they live from their parents, the less frequently they contact them (H3). This hypothesis is supported by the existing empirical evidence, showing that proximity and frequency of contacts are strongly correlated (Greenwell and Bengtson 1997).

Finally, according to the last presented approach, we may expect parent-child differences in educational attainment to have a negative effect on contacts $(\mathrm{H} 4)$ : this may be due to the fact that, as suggested by the literature on assortative mating, individuals tend to structure their relationships according to the homophily principle (McPherson et al. 2001). This means that personal networks are homogeneous with respect to many individual characteristics, such as education. The literature presents a lot of empirical evidence of the existence of this phenomenon in the choice of the partner and in friendship networks (Mare 1991; Kalmijn and Flap 2001). Nevertheless, it is not clear whether this mechanism is at work also in 'innate' relationships, such as the ones with family members.

It is worth noting that the suggested explanations do not take into account the institutional and cultural context, which plays an important role in shaping individuals' behaviors toward family. First, the traditional distinction between "weak" and "strong" family ties draws a line between northern and central Europe on the one hand, and Mediterranean 
countries on the other hand (Reher 1988). As a result of historical processes, in northern and central Europe individualistic values have the priority over the family group, family members leave early the parental home, adult children tend to live rather distant, and parent-child contacts are more sporadic. In contrast, in southern European countries familistic values are widespread, individuals postpone the leaving of parental home, adult children tend to live close to their family, and parent-child contacts are more frequent (Kohli et al. 2005; Tomassini et al. 2004).

Second, in the North of Europe the welfare state provides an extensive assistance of elderly in need, and promotes the independence of young people through various forms of public financial transfers. These institutional incentives favor the autonomy of older and younger generations, thus promoting geographical distance between parents and children. On the contrary, the Mediterranean welfare state hardly provides adequate services for elderly, young people and children. This lack of public incentives enhances the intergenerational dependency of family members; thus, adult children are incentivized to live nearby in order to help their parents and receive support from them (Daatland \& Lowenstein 2005).

Third, job opportunities significantly differ according to the peculiar labor market's structure. Especially the level of labor market rigidity is likely to affect both the availability of vacancies and the wage distribution. In more regulated labor markets, as the Italian one, lower wage incentives and more stable employment relations do not promote individual geographical mobility. Labor market flexibility, in contrast, augments job and wage opportunities related to geographical mobility (Alesina et al. 2010).

In this scenario, we may expect that education plays a different role in shaping attitudes toward family across analyzed countries. In particular, we expect educational differences to have a lower effect on intergenerational distance and contacts in Italy, whereas the association is expected to be positive and higher in Sweden (H5). This may occur because in Scandinavian countries flexible labor market promotes geographical and occupational mobility through the provision of higher economic incentives. On the contrary, in Mediterranean countries, the lack of economic incentives to mobility interacts with a familialistic value orientation, which promotes the closeness between generations, regardless to the individual level of education. France is likely to fall in between since, as we have previously seen, it shares some institutional and cultural features with Mediterranean countries and others with the Scandinavian ones.

\section{Data and methods}

The analysis is based on data from Share (Survey of Health, Ageing and Retirement in Europe) 2004 and 2007, which is a cross-national database of micro data in health, socioeconomic status and social and family networks of more than 85.000 individuals from 19 European countries aged 50 or over. We select individuals residing in Italy, France and Sweden. The analysis is carried out on parent-child dyads in which the children, aged 18 or older, has already left the parental home and is not a student. It is important to note that the proportion of adult children living with parents significantly varies across the three considered countries, going from the $4.8 \%$ in Sweden, to the $12.4 \%$ in France, to the $30.2 \%$ in Italy. It is widely acknowledged that the timing of leaving the parental home significantly differs across European countries, but this topic overtakes the focus of this paper: the analysis of parent-child distance and contacts is indeed meaningful only when looking at children who have already left the parental home ${ }^{1}$.

The Italian sample includes 7,211 dyads and 2,595 individuals (parents); the French one is composed by 9,975 dyads and 3,239 individuals, and, finally, for Sweden we have 10,725 dyads and 3,229 individuals.

The two dependent variables are based on parents' answers to two questions, which respectively ask how far do their children live, and how often do they have contacts with them². The first variable is recoded in kilometers, while the second in days per year.

Tables 1 and 2 report, for each country, the distribution of the two variables, according to children's level of education.

The two main independent variables included in the model are children's level of education and parent-child educational difference. They are both measured in (required) years of schooling.

Controls are also provided for some children's characteristics, namely sex, age, occupational status (employed, not employed, not in the labour market), and marital status (married, divorced, never married).

Table 1 summarizes the association between education and parent-child distance separately for the three

\footnotetext{
${ }^{1}$ It is worth noting that differences in the country-specific rate of individuals leaving the parental home may introduce a selection bias which we are not able to take into account.

2 The variable refers to every kind of parent-child contacts: it is not possible to distinguish between face-to-face, telephonic and mailing contacts.
} 
countries. In general, we observe that the higher the education, the more distant children live from their family. This holds especially in Sweden, where the difference between the lower and the higher educated individuals living more than 100 kilometers far from their parents is almost 20 percentage points. In Italy this difference is quite smaller (10 percentage points), while France falls in between (15 percentage points). Moreover, it is clear-cut the difference in the overall level of parent-child proximity among the three countries, with Italy registering a substantially high proportion of individuals leaving less than 5 kilometers far from their family of origin.

Tab. 1. Parent-child geographical distance (in kilometers) by children's years of education and country.

\begin{tabular}{|c|c|c|c|c|c|c|c|c|c|}
\hline & \multicolumn{3}{|c|}{$\begin{array}{c}\text { Italy } \\
\text { Years of education }\end{array}$} & \multicolumn{3}{|c|}{$\begin{array}{c}\text { France } \\
\text { Years of education }\end{array}$} & \multicolumn{3}{|c|}{$\begin{array}{c}\text { Sweden } \\
\text { Years of education }\end{array}$} \\
\hline & $0-9$ & $9-14$ & $14-20$ & $0-9$ & $9-14$ & $14-20$ & $0-9$ & $9-14$ & $14-20$ \\
\hline$<1$ & 33.7 & 29.6 & 24.6 & 12.4 & 13.0 & 7.5 & 12.4 & 11.5 & 6.2 \\
\hline $1-5$ & 24.2 & 21.9 & 21.1 & 17.3 & 16.7 & 11.0 & 20.0 & 19.6 & 14.7 \\
\hline $5-25$ & 21.8 & 25.6 & 16.7 & 25.3 & 26.3 & 21.2 & 25.2 & 26.8 & 20.3 \\
\hline $25-100$ & 7.0 & 8.9 & 14.2 & 18.0 & 19.3 & 18.4 & 18.5 & 18.6 & 17.7 \\
\hline+100 & 13.3 & 14.0 & 23.4 & 27.0 & 24.8 & 41.9 & 23.9 & 23.6 & 41.0 \\
\hline Total & 100 & 100 & 100 & 100 & 100 & 100 & 100 & 100 & 100 \\
\hline $\mathrm{N}$ & 3,078 & 2,914 & 1,382 & 1,713 & 4,044 & 4,432 & 1,582 & 4,671 & 4,532 \\
\hline
\end{tabular}

Similarly, table 2 shows that Italy significantly differs from the other two countries for the overall higher frequency of contacts: individuals contacting their parents daily are $50 \%$ or more in all the considered educational groups. On the contrary, in Sweden and in France only one over five adult children has daily contacts with his parents, regardless of the educational level. However, from these preliminary descriptive results, it is less clear whether education has an effect on frequency of parent-child contacts. For instance, focusing on the daily contacts' category, we observe a positive influence in Italy, zero effect in France, and negative association in Sweden.

Tab. 2. Frequency of parent-child contacts by children's years of education and country.

\begin{tabular}{|c|c|c|c|c|c|c|c|c|c|}
\hline & \multicolumn{3}{|c|}{$\begin{array}{c}\text { Italy } \\
\text { Years of education }\end{array}$} & \multicolumn{3}{|c|}{$\begin{array}{c}\text { France } \\
\text { Years of education }\end{array}$} & \multicolumn{3}{|c|}{$\begin{array}{c}\text { Sweden } \\
\text { Years of education }\end{array}$} \\
\hline & $0-9$ & $9-14$ & $14-20$ & $0-9$ & $9-14$ & $14-20$ & $0-9$ & $9-14$ & $14-20$ \\
\hline Daily & 49.9 & 59.5 & 59.2 & 21.0 & 22.7 & 21.0 & 21.1 & 22.0 & 13.9 \\
\hline Several times & 25.9 & 25.3 & 26.9 & 25.7 & 32.1 & 25.7 & 30.2 & 38.3 & 42.2 \\
\hline Every week & 13.5 & 9.2 & 8.1 & 19.0 & 23.3 & 18.9 & 25.9 & 22.6 & 28.7 \\
\hline Every 2 week & 4.6 & 2.3 & 2.0 & 9.3 & 7.9 & 9.3 & 7.6 & 7.6 & 7.3 \\
\hline Less often & 6.1 & 3.8 & 3.9 & 25.1 & 13.9 & 25.1 & 15.2 & 9.3 & 7.9 \\
\hline Total & 100 & 100 & 100 & 100 & 100 & 100 & 100 & 100 & 100 \\
\hline $\mathrm{N}$ & 3,078 & 2,914 & 1,382 & 1,713 & 4,044 & 4,432 & 1,582 & 4,671 & 4,532 \\
\hline
\end{tabular}

In order to better understand whether it does exist an association between education and intergenerational relations, despite the unclear descriptive results, we carry out multivariate analyses adopting the so-called 'within family' approach. This consists in comparing parent-child dyads within the same family, by means of fixed effects models. This strategy produces more robust results, since it allows to eliminate the bias deriving from observable and unobservable families' characteristics (Henretta et al. 1997, Kalmijn 2012); these features, such as all the parents' variables, are constant (fixed) between children within the same family, and are therefore removed. This strategy is based on differences between siblings; thus, only families with at least two children and with variation in the outcome variables are included. Table 3 reports the number of individuals and dyads that respect these two conditions.

Tab. 3. Number of dyads and families included in the analysis by country. 


\begin{tabular}{cccc}
\hline & Italy & France & Sweden \\
\hline Number of dyads & 4,816 & 6,615 & 7,320 \\
Number of families & 2,470 & 3,131 & 3,360 \\
\hline
\end{tabular}

\section{Results}

Table 4 and $5(a, b$, and $c)$ present the results of the multivariate analysis. Geographical distance and frequency of contacts are treated as continuous variables, as suggested by the literature (Kalmijn 2006; Leopold 2012). This analysis is based on the comparison between siblings, and thus the reported coefficients have to be interpreted as the variation in the outcome variables associated with the variation in siblings' characteristics.

Table 4 shows a positive association between children's level of education and their distance from the parental home in Sweden and France. In the first case, one more year of schooling produce an increase of the distance of more than 3.6 kilometers; in the second case, the distance augment of about 1.7 kilometers per year of additional education. In contrast, the coefficient is not statistically significant in Italy, suggesting that residential proximity between generations is not affected by children's education. These results support our first hypothesis only for Sweden and France. As previously suggested $(\mathrm{H} 5)$, though, it seems that the institutional and cultural context does play a role in shaping the structure of costs and opportunities related to geographical mobility.

Moreover, the results suggest that distance from the parental home is likely to be affected by different individual characteristics in different countries. In Italy, female tend to reside closer to parents than their brothers: this may reflect a well-known gender gap in care responsibilities and provision (Saraceno 1994). In France, one important variable is age: older children are more likely to reside nearer the parental home. Finally, in Sweden we observe that unemployed children live significantly closer to their parents than their employed siblings.

Tab. 4. Models of linear regression on parent-child geographical distance, fixed effects.

\begin{tabular}{lccc}
\hline & Italy & France & Sweden \\
\hline Years of education & 0.958 & $1.722^{\star}$ & $3.606^{\star \star \star}$ \\
Female & $(1.472)$ & $(0.749)$ & $(1.094)$ \\
& $-24.299^{\star \star \star}$ & 0.601 & -1.457 \\
Age & $(6.162)$ & $(5.233)$ & $(4.468)$ \\
& -0.482 & $-1.334^{\star}$ & -0.854 \\
Unemployed & $(0.680)$ & $(0.658)$ & $(0.505)$ \\
& -33.434 & -4.786 & $-30.554^{\star}$ \\
Not in LM & $(17.129)$ & $(12.601)$ & $(12.438)$ \\
& -9.350 & 0.861 & 16.025 \\
Never married & $(8.476)$ & $(8.450)$ & $(9.205)$ \\
& 16.487 & 3.042 & 4.226 \\
Divorced & $(9.947)$ & $(6.532)$ & $(6.000)$ \\
& 16.262 & -17.194 & -1.026 \\
& $(18.025)$ & $(10.535)$ & $(9.304)$ \\
Constant & & & \\
& $1,045.685$ & $2,730.482^{\star}$ & $1,744.225$ \\
& $(1,335.544)$ & $(1,292.617)$ & $(992.039)$ \\
Observations & & & \\
R-squared & 4,816 & 6,615 & 7,320 \\
Number of families & 0.014 & 0.004 & 0.006 \\
\hline
\end{tabular}

Note: Standard errors in parentheses

*** $p<0.001,{ }^{* *} p<0.01,{ }^{*} p<0.05$

Tables $5 a, 5 b$ and $5 c$ report the association between the frequency of child-parent contacts and a number of individual characteristics, education above all. For each country, we implement three models: the first includes adult children's years of education, in the second child-parent proximity is added and the third shows the effect of educational homogamy.

Focusing on Italy, table 5a does not show any significant effect of children's years of schooling (model 1). 
Education is not significantly associated with contacts even when controlling for distance from the parental home, which on the contrary is negatively correlated with the dependent variable (model 2). Moreover, we do not find a significant effect of parent-child educational difference on contacts. While we expected a little association between education and the frequency of contacts (H5), Italy presents a widespread closeness between generations. These results (see also table 4) depict Italy as a country largely dominated by familialistic values and attitudes, where also the higher educated children tend to remain close to their families and to maintain strong ties with parents. Moreover, in Italy the costs of moving in order to find better job opportunities overwhelm the benefits deriving from staying close to the family and accept the vacancies in the initial location.

Tab. 5a. Models of linear regression on frequency of parent-child contacts in Italy, fixed effects.

\begin{tabular}{lccc}
\hline & $(1)$ & $(2)$ & $(3)$ \\
\cline { 2 - 4 } Years of education & 0.689 & 0.926 & \\
Distance & $(1.171)$ & $(1.113)$ & \\
& & $-0.248^{\star \star \star}$ & \\
Educational difference & & $(0.016)$ & 0.633 \\
& & & $(1.237)$ \\
Female & $30.047^{\star \star \star}$ & $24.027^{\star \star \star}$ & $30.140^{\star \star \star}$ \\
& $(4.904)$ & $(4.676)$ & $(4.894)$ \\
Age & $1.852^{\star \star \star}$ & $1.733^{\star \star \star}$ & $1.851^{\star \star \star}$ \\
Unemployed & $(0.541)$ & $(0.515)$ & $(0.542)$ \\
& 10.927 & 2.644 & 10.621 \\
Not in LM & $(13.630)$ & $(12.966)$ & $(13.604)$ \\
& 12.323 & 10.007 & 12.192 \\
Never married & $(6.745)$ & $(6.413)$ & $(6.730)$ \\
Divorced & $-36.315^{\star \star *}$ & $-32.230^{\star \star \star}$ & $-36.360^{\star \star \star}$ \\
& $(7.916)$ & $(7.528)$ & $(7.923)$ \\
& -3.673 & 0.355 & -3.620 \\
Constant & $(14.343)$ & $(13.636)$ & $(14.347)$ \\
& & & \\
& $-3,447.996^{\star \star}$ & $-3,188.939^{\star \star}$ & $-3,439.805^{\star \star}$ \\
Observations & $(1,062.759)$ & $(1,010.291)$ & $(1,063.965)$ \\
R-squared & 4,816 & 4,816 & 4,816 \\
Number of families & 0.040 & 0.133 & 0.040 \\
Nrors in parentheses & 2,470 & 2,470 & 2,470 \\
\hline
\end{tabular}

Note: Standard errors in parentheses

*** $p<0.001,{ }^{* *} p<0.01,{ }^{*} p<0.05$

Table $5 b$ shows a similar pattern in France, where education does not seem to have a significant effect on the frequency of parent-child contacts (model 1), even when controlling for children's distance from the parental home (model 2). In France, however, we find a statistically significant and negative effect of parent-child educational difference, in accordance with our fourth hypothesis: the higher the difference between the years of schooling of children and that of parents, the less frequent are their contacts. According to the literature, this may be due to the fact that people with different levels of education develop a different system of preferences and interests, which may affect the type and the strength of their relationships.

Tab. $\mathbf{5 b}$. Models of linear regression on frequency of parent-child contacts in France, fixed effects.

\begin{tabular}{|c|c|c|c|}
\hline & (1) & (2) & (3) \\
\hline Years of education & $\begin{array}{c}0.433 \\
(0.509)\end{array}$ & $\begin{array}{c}0.668 \\
(0.500)\end{array}$ & \\
\hline Distance & & $\begin{array}{c}-0.136^{\star \star \star} \\
(0.011)\end{array}$ & \\
\hline Educational difference & & & $\begin{array}{c}-1.359^{x} \\
(0.588)\end{array}$ \\
\hline
\end{tabular}




\begin{tabular}{lccc} 
Female & $25.381^{\star \star \star}$ & $25.462^{\star \star \star}$ & $25.544^{\star \star \star}$ \\
Age & $(3.558)$ & $(3.487)$ & $(3.547)$ \\
& $2.473^{\star \star \star}$ & $2.291^{\star \star \star}$ & $2.480^{\star \star \star}$ \\
Unemployed & $(0.447)$ & $(0.439)$ & $(0.447)$ \\
& $23.689^{\star \star}$ & $23.037^{\star \star}$ & $22.769^{\star \star}$ \\
Not in LM & $(8.569)$ & $(8.396)$ & $(8.543)$ \\
& $14.079^{\star}$ & $14.196^{\star}$ & $12.359^{\star}$ \\
Never married & $(5.746)$ & $(5.630)$ & $(5.702)$ \\
& 7.141 & 7.555 & 7.134 \\
Divorced & $(4.441)$ & $(4.352)$ & $(4.436)$ \\
& $15.981^{\star}$ & 13.638 & $14.989^{\star}$ \\
Constant & $(7.163)$ & $(7.022)$ & $(7.149)$ \\
& & & \\
& $-4,770.291^{\star \star \star}$ & $-4,398.228^{\star \star \star}$ & $-4,771.8911^{\star \star \star}$ \\
Observations & $(878.970)$ & $(861.817)$ & $(878.336)$ \\
R-squared & & & \\
Number of id & 6,615 & 6,615 & 6,615 \\
N & 0.031 & 0.070 & 0.033 \\
\hline
\end{tabular}

Note: Standard errors in parentheses

*** $p<0.001,{ }^{* *} p<0.01,{ }^{*} p<0.05$

Finally, table $5 \mathrm{c}$ shows a strong and negative effect of years of schooling on contacts in Sweden: this indicates that, according to our second hypothesis, individuals with a higher level of education have less frequent contacts with their parents than their less educated siblings. This negative association holds even when controlling for the distance from the parental home $(\mathrm{H} 3)$, even though part of the education's effect seems to be absorbed by distance. It is possible to interpret these findings as the result of a complex mix of labour market opportunities and individualistic value orientation. On the one hand, education indirectly affects the frequency of contacts through the distance from the parental home: higher educated individuals are more likely to move in order to catch the job opportunities offered by a geographicallydelimited labour market, and thus they have less intergenerational contacts. On the other hand, education directly affects contacts by spreading individualistic attitudes and behaviors: the higher educated individuals are less family-oriented than the lower educated, and thus they have less frequent contacts with their parents.

The educational difference between parents and children, in contrast, is found not to have a statistically significant effect on contacts.

Tab. 5c. Models of linear regression on frequency of parent-child contacts in Sweden, fixed effects.

\begin{tabular}{|c|c|c|c|}
\hline & (1) & (2) & (3) \\
\hline Years of education & $\begin{array}{c}-2.173^{\star \star} \\
(0.767)\end{array}$ & $\begin{array}{l}-1.486^{*} \\
(0.740)\end{array}$ & \\
\hline Distance & & $\begin{array}{c}-0.191^{\star \star *} \\
(0.011)\end{array}$ & \\
\hline Educational difference & & & $\begin{array}{l}-0.892 \\
(0.813)\end{array}$ \\
\hline Female & $\begin{array}{c}34.645^{\star \star *} \\
(3.133)\end{array}$ & $\begin{array}{c}34.367^{\star \star \star} \\
(3.016)\end{array}$ & $\begin{array}{c}33.895^{\star * *} \\
(3.123)\end{array}$ \\
\hline Age & $\begin{array}{c}2.192^{\star \star *} \\
(0.354)\end{array}$ & $\begin{array}{c}2.029^{* * *} \\
(0.341)\end{array}$ & $\begin{array}{c}2.170^{\star \star \star} \\
(0.354)\end{array}$ \\
\hline Unemployed & $\begin{array}{c}25.861^{* *} \\
(8.722)\end{array}$ & $\begin{array}{l}20.039^{*} \\
(8.401)\end{array}$ & $\begin{array}{c}27.488^{\star \star} \\
(8.709)\end{array}$ \\
\hline Not in LM & $\begin{array}{c}9.409 \\
(6.455)\end{array}$ & $\begin{array}{c}12.463^{*} \\
(6.215)\end{array}$ & $\begin{array}{l}11.985 \\
(6.385)\end{array}$ \\
\hline Never married & $\begin{array}{l}9.164^{*} \\
(4.207)\end{array}$ & $\begin{array}{l}9.969^{\star} \\
(4.050)\end{array}$ & $\begin{array}{l}9.678^{\star} \\
(4.206)\end{array}$ \\
\hline Divorced & $\begin{array}{c}4.479 \\
(6.524)\end{array}$ & $\begin{array}{c}4.284 \\
(6.279)\end{array}$ & $\begin{array}{c}4.946 \\
(6.530)\end{array}$ \\
\hline Constant & $-4,191.891^{\star \star \star}$ & $-3,859.544^{\star \star \star}$ & $-4,173.410^{\star \star \star}$ \\
\hline
\end{tabular}


(695.642)

$\begin{array}{cc}\text { Observations } & 7,320 \\ \text { R-squared } & 0.046 \\ \text { Number of id } & 3,360 \\ \text { Note: Standard errors in parentheses } & \\ { }^{* * \star} p<0.001,{ }^{* \star} p<0.01,{ }^{*} p<0.05 & \end{array}$

(669.814)

(696.503)

$\begin{array}{lll}720 & 7,320 & 7,320 \\ .046 & 0.117 & 0.045 \\ 360 & 3,360 & 3,360\end{array}$

\section{Conclusions}

This paper has focused on the effect of education on the strength of family ties, measured through parent-child geographical distance and frequency of contacts. The maintenance of close intergenerational relations is a central topic in the actual sociological research, especially because of the process of ageing which is nowadays affecting the developed western societies (Bengtson 2001).

The literature pinpoints two main channels through which education may influence the strength of intergenerational ties. On the one hand, structural explanations focus on the system of constraints and opportunities especially deriving from the labour market and the welfare state. On the other hand, cultural explanations focus on the system of values and attitudes towards family.

We have argued that these two explanations are more-or-less consistent with country-specific contexts; this hypothesis is confirmed by the results, which suggest the existence of different patterns of association between education and our dependent variables in the three considered countries. In Italy, where the well-known predominant familialism combines with a few labour market opportunities and a sub-protective welfare state, we observe frequent intergenerational contacts and closeness to the parental home, regardless of the individual educational attainment. In Sweden, on the contrary, a widespread individualism makes the intergenerational bonds weaker, especially among higher educated individuals, who also have more job opportunities in (geographically) specific labor markets. As hypothesized, France falls somewhere in between, with a small effect of education on distance, and only a weak association - not found elsewhere - between parent-child educational difference and frequency of contacts.

\section{References}

Alesina, A.F., Algan, Y., Cahuc, P. \& Giuliano, P. (2010), Family Values and the Regulation of Labor, NBER Working Paper 15747. Beck, U. (1986). Risikogesellschaft. Auf dem Weg in eine andere Moderne, Suhrkamp Verlag Gmbh: Neuauflage.

Bengtson, V.L. (2001). Beyond the nuclear family: The increasing importance of multigenerational bonds, Journal of Marriage and Family, 63(1), 1-16.

Daatland, S.O. \& Lowenstein, A. (2005). Intergenerational solidarity and the family-welfare state balance, European Journal of Ageing, vol.2, pp.174-182.

Gallie, D. \& Paugam, S. (2000). Welfare regimes and the experience of unemployment in Europe, Oxford: Oxford University Press.

Greenwell, L. \& Bengtson, V. L. (1997). Geographic distance and contact between middle-aged children and their parents: The effects of social class over 20 years. Journal of Gerontology: Social Sciences, 52B, S13-S26.

Henretta, J. C., Hill, M. S., Li, W., Soldo, B. J. \& Wolf, D. A. (1997). Selection of children to provide care: The effect of earlier parental transfers, The Journals of Gerontology, 52, 110-119.

Hout, M. (2012). Social and Economic Returns to College Education in the United States, Annual Review of Sociology, 38, 379-400.

Inglehart, R. (1997). Modernization and Postmodernization: Cultural, Economic and Political Change in 43 Societies, Princeton: Princeton University Press.

Kalmijn, M (2006). Educational inequality and family relationships: Influences on contact and proximity, European Sociological Review, 22(1), 1-16.

Kalmijn, M., \& Flap, H. (2001). Assortative meeting and mating: unintended consequences of organized settings for partner choices. Social Forces, 79(4), 1289-1312.

Kalmijn, M. \& Saraceno, C. (2008). A comparative perspective on intergenerational support. Responsiveness to parental needs in individualistic and familialistic countries, European Societies, 10, 479-508.

Klein Ikkink, K., van Tilburg, T., \& Knipscheer, K. C. P. M. (1999). Perceived instrumental support exchanges in relationships between elderly parents and their adult children: normative and structural explanations. Journal of Marriage and Family, 61(4), 831-844.

Kohli, M. (1999). Private and public transfers between generations: Linking the family and the state, European Societies, 1, 81-104.

Kohli, M. (2005). Generational Changes and Generational Equity, in M. Johnson, V. L. Bengtson, P. G. Coleman \& T. B. L. Kirkwood (Eds.), The Cambridge Handbook of Age and Ageing, (pp. 518-26), Cambridge: Cambridge University Press.

Leopold, T. (2012). The legacy of Leaving Home: Long-Terms Effects of Coresidence on Parent-Child Relationships, Journal of Marriage and Family, 74(3), 399-412. 
Litwak, E. (1960). Occupational mobility and extended family cohesion, American Sociological Review, 25, 9-21.

Mare, R.D. (1991). Five Decades of Educational Assortative Mating, American Sociological Review, 56(1), 15-32.

McPherson M., Smith-Lovin, L., \& Cook, J. M. (2001). Birds of a feather: homophily in social networks. Annual Review of Sociology, 27, 415-444

Parsons, T. (1942). Age and sex in the social structure of the United States, American Sociological Review, 7, 604-16.

Popenoe, D. (1993). American family decline 1960-1990: a review and appraisal, Journal of Marriage and the Family, 55, 527-55.

Reher, D. S. (1998). Family ties in Western Europe: Persistent contrasts, Population and Development Review, 24, $203-234$.

Saraceno, C. (1994), The Ambivalent Familism of Italian Welfare State, Social Politics, 1(1), 60-82.

Shelton, N. \& Grundy, E. (2000). Proximity of Adult Children to their Parents in Great Britain, International Journal of Population Geography, 6, 181-195.

Thornton, A. \& Young-DeMarco, L. (2001). Four Decades of Trends in Attitudes Toward Family Issues in the United States, Journal of Marriage and the Family, 63, 1009-1037.

Tomassini, C., Wolf, D.A., \& Rosina, A. (2004) Parental Housing Assistance and Parent-child Proximity in Italy, Journal of Marriage and the Family, 65(3),700-15. 